\title{
PENGARUH UKURAN PARTIKEL TERHADAP SIFAT KEMAGNETAN MATERIAL MAGNET KOMPOSIT BaFe ${ }_{12} \mathrm{O}_{19} / \alpha \mathrm{Fe}$
}

Erfan Handoko ${ }^{1}$, Setia Budi ${ }^{2}$ dan Bambang Soegijono ${ }^{3}$

${ }_{1}$ Jurusan Fisika, Fakultas Matematika dan Ilmu Pengetahuan Alam, Universitas Negeri Jakarta, Jl. Pemuda No.10 Rawamangun Jakarta, Indonesia

2 Jurusan Kimia, Fakultas Matematika dan IImu Pengetahuan Alam, Universitas Negeri Jakarta, Jl. Pemuda No.10 Rawamangun Jakarta, Indonesia

3 Departemn Fisika, Fakultas Matematika dan IImu Pengetahuan Alam, Universitas Indonesia, Depok, Indonesia

Corresponding Author: erfisika92@gmail.com

\begin{abstract}
Abstrak
Pembentukan material magnet komposit yang terdiri serbuk barium heksaferat, $\mathrm{BaFe}_{12} \mathrm{O}_{19}$, dan serbuk besi BCC, $\alpha \mathrm{Fe}$, dengan perbandingan 60:40 \% berat telah dilakukan. Proses penghalusan ukuran partikel magnet komposit dengan menggunakan planetary ball mill (PBM) dalam suasana toluen selama 30 jam bertujuan untuk meningkatkan sifat kemagnetan. Identifikasi fasa magnet komposit diperoleh hasil pengukuran dengan difraksi sinar-X radiasi $\mathrm{K} \alpha$ Co. Foto morfologi bentuk partikel magnet komposit menggunakan scanning electron microscope (SEM) 5310LV Jeol pada perbesaran 2000 kali. Distribusi ukuran partikel diketahui dengan LS Particle Size Analyzer (PSA) Beckman Coulter dan sifat kemagnetan dianalisis dengan alat Permagraph pada temperatur kamar. Hasil pengukuran menunjukkan bahwa selama penghalusan ukuran partikel material magnet komposit melalui proses milling tidak terjadi dekomposisi fasa, distribusi ukuran serbuk cendrung menurun dengan bertambahnya waktu milling. Pengaruh terhadap sifat kemagnetan material magnet komposit $\mathrm{BaFe}_{12} \mathrm{O}_{19} / \alpha \mathrm{Fe}$ yang mengalami penurunan magnetisasi sisa atau remanen dari 0,32 T menjadi 0,15 T dan nilai koersivitas magnetik 228,3 kA/m menjadi 42,5 kA/m. Namun nilai magnetisasi saturasi cendrung meningkat dari 0,59 T menjadi 0,80 T.
\end{abstract}

Kata Kunci : Magnet komposit, ukuran partikel, sifat kemagnetan, $\mathrm{BaFe}_{12} \mathrm{O}_{19} / \alpha \mathrm{Fe}$.

\begin{abstract}
The formation of magnetic composite material by combaining barium hexaferrite, $\mathrm{BaFe}_{12} \mathrm{O}_{19}$, and $\alpha \mathrm{Fe}$ powder with 60:40 \% wt ratio has been investigated. The refinement of particle size of composite magnet by using planetary ball mill (PBM) for 30 hours in toluena atmosphere in order to enhance the magnetic properties. Phase identification of magnetic composite was examined by X-Ray Diffractometer (XRD) Phillips with KaCo radiation. The morfology of magnetic composite particle was studied using a scanning electron microscope (SEM) 5310LV Jeol.The particle distribution is measured LS Particle Size Analyzer (PSA) Beckman Coulter and the magnetic properties is measured by Permagraph at the room temperature. The results show that in milling process, the phase decomposition is not found, and particle size distribution is decrease. Influence on magnetic properties of magnetic composite material $\mathrm{BaFe}_{12} \mathrm{O}_{19} / \alpha \mathrm{Fe}$ are decrease remanen (Mr) from 0,32 $\mathrm{T}$ to $0,15 \mathrm{~T}$ and also the coercivity ( $\mathrm{Hc}$ ) from $228,3 \mathrm{kA} / \mathrm{m}$ to $42,5 \mathrm{kA} / \mathrm{m}$. But the saturation magnetization (Ms) increase from 0,59 $\mathrm{T}$ to $0,80 \mathrm{~T}$.
\end{abstract}

Keywords : Composite magnet, particle size, magnetic properties, $\mathrm{BaFe}_{12} \mathrm{O}_{19} / \alpha \mathrm{Fe}$.

\section{Pendahuluan}

Penelitian dan pengembangan material magnet permanen berbasis sistem keramik (Ba,Sr)O.6 $\mathrm{Fe}_{2} \mathrm{O}_{3}$ masih terus dilakukan[1,2]. Komposisi sistem barium heksaferat $\mathrm{BaFe}_{12} \mathrm{O}_{19}$ dalam aplikasinya sebagai magnet permanen cukup luas digunakan sampai saat ini sejak dipublikasikan oleh Phillips [3]. Material magnet permanen sistem $\mathrm{BaFe}_{12} \mathrm{O}_{19}$ yang jumlahnya pemakaian dalam aplikasi lebih dari $50 \%$ menjadi peluang untuk dikembangkan. Namun demikian magnet permanen tersebut tidak memiliki sifat kemagnetan yang cukup besar dibandingkan dengan jenis magnet logam tanah jarang. Rekayasa struktur $\mathrm{BaFe}_{12} \mathrm{O}_{19}$ dengan tujuan meningkatkan sifat 
kemagnetan sampai saat ini terus berjalan oleh banyak peneliti [4-8]. Proses preparasi baik itu teknik konvensional seperti Powder Metallurgy[9] maupun rekayasa dalam proses pembentukan [10-12] telah mampu menghasilkan sifat kemagnetan ekstrinsik yang optimal. Hal ini menunjukkan bahwa seolaholah jenis-jenis senyawa magnetik ini menjadi sangat mendesak untuk dikembangkan.

Dalam penelitian telah dilakukan rekayasa struktur magnet barium heksaferat, $\mathrm{BaFe}_{12} \mathrm{O}_{19}$, dengan tidak merubah komposisi kimianya melainkan mengkombinasikan dengan magnet lunak ? $\mathrm{Fe}$ dan dilanjutkan dengan proses penghalusan ukuran partikel dengan menggunakan proses milling dalam suasana toluen. Kombinasi dua jenis material magnet ini disebut magnet komposit $\mathrm{BaFe}_{12} \mathrm{O}_{19} /$ ?]Fe tidak terjadi perubahan fasa setelah proses milling dan terjadi kenaikan magnetisasi saturasi (Ms) yang disebabkan adanya fasa $\alpha \mathrm{Fe}$.

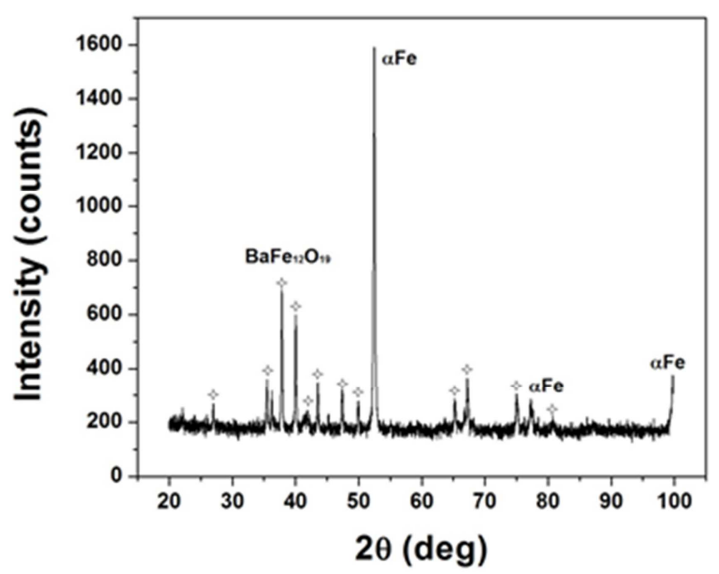

Gambar 1. Pola difraksi sinar-X $\mathrm{BaFe}_{12} \mathrm{O}_{19} / \alpha \mathrm{Fe}$ setelah proses Milling selama 10 jam.

\section{Metodologi Penelitian}

Material magnet komposit $\mathrm{BaFe}_{12} \mathrm{O}_{19} /$ [? $\mathrm{Fe}$ dengan perbandingan berat $60 \%$ dan $40 \%$ disiapkan dengan proses milling dengan planetary ball mill (PBM) selama 30 jam dalam suasana basah cairan toluen. Identifikasi fasa campuran setelah proses milling diukur dengan Phillips difraksi sinar- $X$ radiasi $\mathrm{Co} K$ ? pada interval sudut (2]) $20^{\circ}-100^{\circ}$. Pengamatan morfologi partikel hasil milling selama 10 jam, 20 jam, dan 30 jam menggunakan scanning electron microscope (SEM) 5310LV Jeol dengan perbesaran 2000 kali. Distribusi ukuran partikel setelah proses milling diketahui dengan LS Particle Size Analyzer (PSA) Beckman Coulter. Kurva histerisis dihasilkan dengan alat Permagraph pada temperatur kamar dan medan magnet luar maksimum $2 \mathrm{~T}$ bertujuan untuk mengetahui sifat kemagnetan magnet komposit.

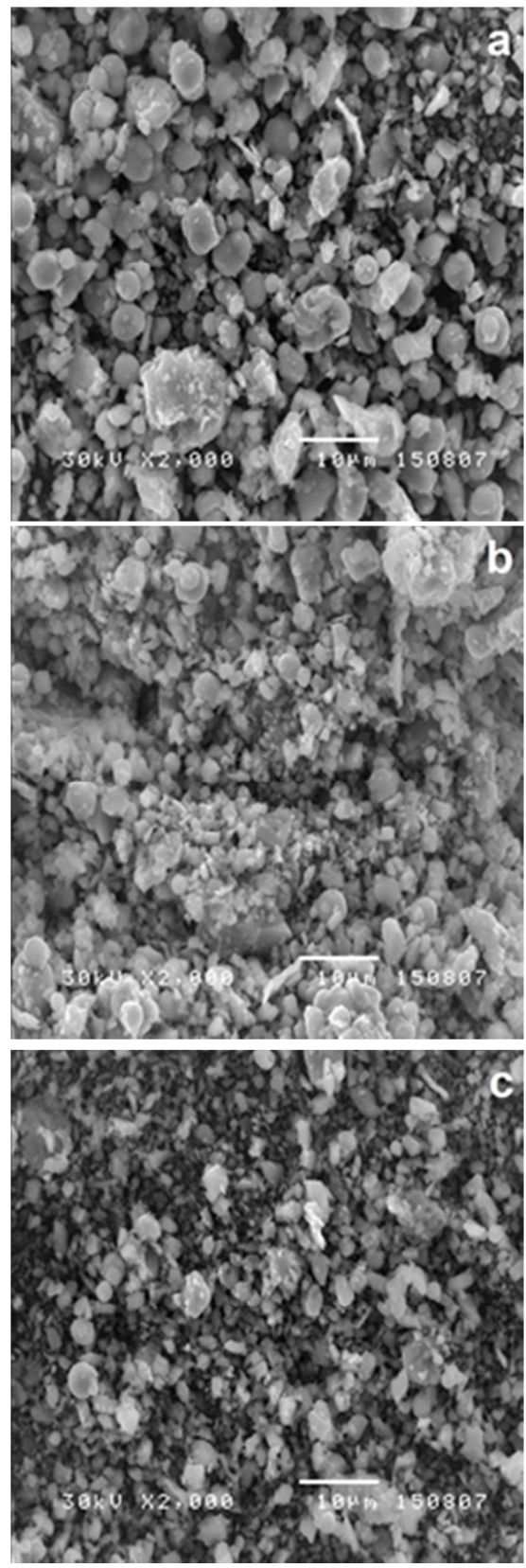

Gambar 2. Foto SEM morfologi struktur mikro magnet komposit $\mathrm{BaFe}_{12} \mathrm{O}_{19}$ /? $\mathrm{Fe}$ setelah milling (a). 10 jam, (b). 20 jam, dan (c) 30 jam. 
Tabel 1. Distribusi ukuran partikel magnet komposit BaFe12019/ $\alpha$ Fe setelah milling 10 jam, 20 jam, dan 30 jam.

\begin{tabular}{ccccccccc}
\hline Waktu & \multicolumn{7}{c}{ Distribusi Ukuran Partikel dalam Fraksi Volume (\%) } \\
\cline { 2 - 8 } Milling (Jam) & $<0.4 \mu \mathrm{m}$ & $<0.6 \mu \mathrm{m}$ & $<1 \mu \mathrm{m}$ & $<2 \mu \mathrm{m}$ & $<6 \mu \mathrm{m}$ & $<10 \mu \mathrm{m}$ & $<20 \mu \mathrm{m}$ & $<40 \mu \mathrm{m}$ \\
\hline 10 & 0.36 & 7.65 & 21.1 & 29.1 & 32.8 & 46.1 & 95.7 & 100 \\
20 & 0.49 & 9.79 & 31.2 & 45.9 & 56.6 & 75.3 & 93.8 & 100 \\
30 & 0.5 & 10.1 & 20 & 20.1 & 41.9 & 100 & 100 & 100 \\
\hline
\end{tabular}

Tabel 2. Perbandingan sifat kemagnetan BaFe12019 dan magnet komposit BaFe12019/ $\alpha$ Fe setelah milling 30 jam.

\begin{tabular}{|c|c|c|c|}
\hline \multirow[b]{2}{*}{ Material Magnet } & \multicolumn{3}{|c|}{ Sifat Kemagnetan } \\
\hline & $\begin{array}{c}\text { Magnetisasi Saturasi } \\
\text { (Ms), T }\end{array}$ & $\begin{array}{c}\text { Remanen } \\
(\mathrm{Mr}), \mathrm{T}\end{array}$ & $\begin{array}{l}\text { Koersivitas } \\
\text { (Hc), kA/m }\end{array}$ \\
\hline $\mathrm{BaFe}_{12} \mathrm{O}_{19}$ & 0,59 & 0,32 & 228,3 \\
\hline $\begin{array}{c}\mathrm{BaFe}_{12} \mathrm{O}_{19} / \text { 国Fe Milling } \\
30 \mathrm{Jam}\end{array}$ & 0,80 & 0,15 & 42,5 \\
\hline
\end{tabular}

\section{Hasil dan Pembahasan}

Identifikasi fasa magnet komposit $\mathrm{BaFe}_{12} \mathrm{O}_{19} /$ aFe.

Material magnet komposit yang merupakan campuran $60 \%$ berat $\mathrm{BaFe}_{12} \mathrm{O}_{19}$ dan $40 \%$ berat $\alpha F e$ setelah proses milling selama 10 jam dilakukan analisis kualitatif dengan difraksi sinar-x. Hasil identifikasi fasa menunjukkan tidak terjadi dekomposisi fasa $\mathrm{BaFe}_{12} \mathrm{O}_{19}$ dan $\alpha F e$. Pola difraksi sinar- $X$ magnet komposit setelah proses milling selama 10 jam ditunjukkan pada gambar 1 .

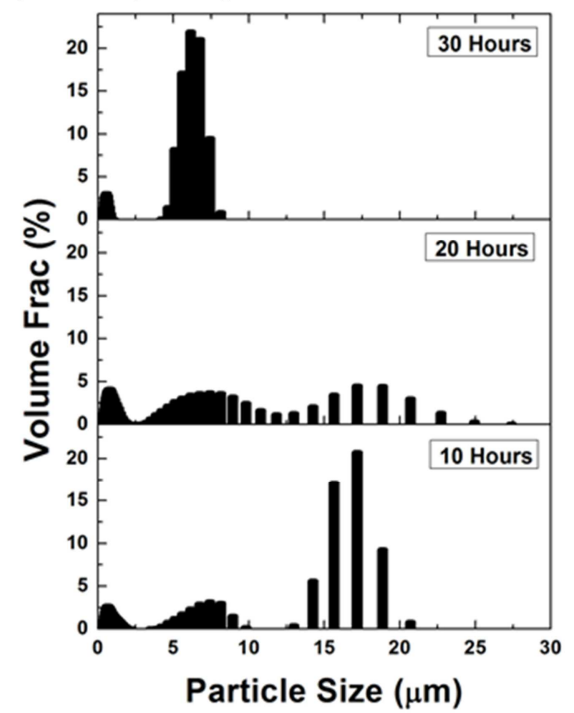

Gambar. 3. Grafik distribusi ukuran partikel magnet komposit $\mathrm{BaFe}_{12} \mathrm{O}_{19} / \alpha \mathrm{Fe}$ setelah milling 10 jam, 20 jam, dan 30 jam.
Pengamatan puncak-puncak difraksi untuk masing-masing fasa memperlihatkan tingginya intensitas puncak dan tidak terjadinya pelebaran puncak secara signifikan. Ini membuktikan struktur kristal masih dipertahankan dan proses milling selam 10 jam belum cukup mereduksi ukuran partikel magnet komposit.

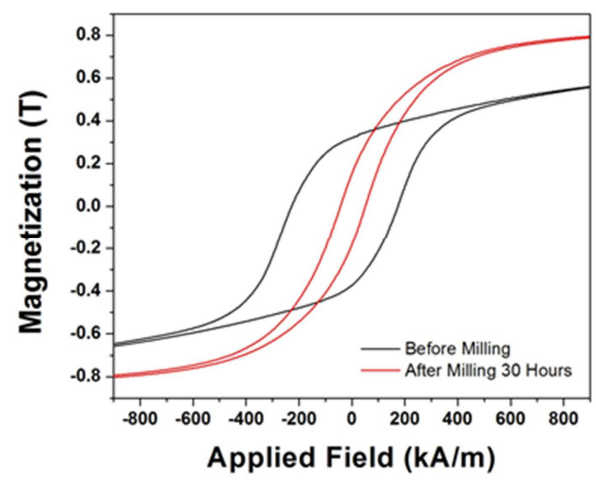

Gambar 4. Kurva histerisis material magnet $\mathrm{BaFe}_{12} \mathrm{O}_{19}$ (sebelum Milling) dan komposit $\mathrm{BaFe}_{12} \mathrm{O}_{19} / \alpha \mathrm{Fe}$ setelah milling 30 jam.

\section{Morfologi dan distribusi ukuran partikel}

Foto SEM memperlihatkan morfologi partikel magnet komposit setelah proses milling 10 jam, 20 jam, dan 30 jam pada perbesaran 2000 kali. Partikel magnet komposit dengan ukuran kurang dari 10 ?m dan mengalami reduksi ukurannya dengan 
bertambahnya waktu milling (gambar 2). Gambar 3 merupakan hasil pengukuran distribusi partikel dengan PSA. Distribusi ukuran partikel magnet serbuk dengan variasi waktu milling membuktikan telah terjadi reduksi ukuran partikel terutama di interval kurang dari 0,6 ?m (tabel 1). Di samping pengaruh milling yang menyebabkan terjadinya reduksi ukuran partikel dan bertambahnya luas permukaan partikel, juga adanya residual stress menyebabkan kristal dalam keadaan tidak sempurna.

\section{Sifat kemagnetan}

Gambar 4 adalah perbandingan antara kurva histerisis magnet $\mathrm{BaFe}_{12} \mathrm{O}_{19}$ sebelum proses milling dan komposit $\mathrm{BaFe}_{12} \mathrm{O}_{19} / \alpha \mathrm{Fe}$ setelah milling selama 30 jam. Tabel 2 menunjukkan nilai sifat kemagnetan yang diturunkan dari kurva histerisis. Pengaruh proses milling yang mengakibatkan reduksi ukuran partikel telah menyebabkan terjadi perubahan nilai sifat kemagnetan. Hasil perbandingan antara magnet sebelum dan sesudah milling selama 30 jam adalah terjadi penurunan koersivitas magnetik $(\mathrm{Hc})$ dari $228,3 \mathrm{kA} / \mathrm{m}$ menjadi $42,5 \mathrm{kA} / \mathrm{m}$ dan magnetisasi sisa atau remanen ( $\mathrm{Mr}$ ) dari 0,32 T menjadi 0,15 T. Sedangkan nilai magnetisasi saturasi (Ms) meningkat sampai $0,80 \mathrm{~T}$ dari $0,59 \mathrm{~T}$ sebagai pengaruh dari pengecilan ukuran partikel dan juga adanya fasa ?Fe yang memiliki Ms yang lebih dari $2 \mathrm{~T}$.

\section{Kesimpulan}

Pembentukan material magnet komposit $\mathrm{BaFe}_{12} \mathrm{O}_{19} / \mathrm{Fe}$ dengan proses milling telah berhasil dilakukan. Proses milling dengan waktu 30 jam secara signifikan berpengaruh terhadap reduksi ukuran partikel dan mengakibatkan perubahan sifat kemagnetan. Perubahan koersivitas magnetik (Hc) dari $228,3 \mathrm{kA} / \mathrm{m}$ menjadi $42,5 \mathrm{kA} / \mathrm{m}$ dan remanen (Mr) dari 0,32 $\mathrm{T}$ menjadi $0,15 \mathrm{~T}$, serta meningkatnya magnetisasi saturasi (Ms) sampai 0,80 $\mathrm{T}$ dari 0,59 $\mathrm{T}$ akibat dari pengecilan ukuran partikel dan juga adanya fasa ?Fe yang memiliki Ms yang lebih dari $2 \mathrm{~T}$.

\section{Penghargaan}

Peneliti mengucapkan banyak terima kasih kepada Dr. Bambang Soegijono, Departemen Fisika Universitas Indonesia atas fasilitas laboratorium fisika material yang mendukung penelitian ini.

\section{Daftar Pustaka}

[1] K.H.J. Buschow, Mat. Sci. Reports, 1 (1986), pp 1-64

[2] H.A. Davies, in Rapidly Quenched Metals III, ed. B.Cantor, 1, the Chameleon Press Ltd, London (1988), pp 8-14

[3] J.Smit, H.P.J.Wijn, Ferrite, Philips Tech.Lib., Eindhoven,1960.

[4] K.S. Martirosyan, E.Galstyan, S.M.Hossain, Yi-Ju Wang, D.Litvinov. Materials Science and Engineering B 176(2011) 8-13

[5] Jianxun Qiu, Mingyuan Gu. Journal of Alloys and Compounds 415 (2006) 209-212

[6] Lixi Wang, Qitu Zhang. Journal of Alloys and Compounds 469 (2009) 251-257

[7] Ping Xu, Xijiang Han, HongtaoZhao, Zhihua Liang, Jinfu Wang. Materials Letters 62 (2008) 1305-1308

[8] Erfan Handoko, Iwan Sugiharto, Zulkarnain Jalil, Bambang Soegijono. Jurnal Riset Sain dan Kimia Terapan (JRSKT) Vol. 3. 1 Juli 2013.

[9] R. Skomski and J.M.D. Coey, IEEE Trans. Magn., 29 (1993), 2860

[10] V.Berbenni, A.Marini, N.J.Welham, P.Galinetto, M.C.Mozzati. Journal of the European Ceramic Society 23 (2003)179-187

[11] Hüseyin Sözeri. Journal of Alloys and Compounds 486 (2009) 809-814

[12] Ugur Topal, Husnu Ozkan, Huseyin Sozeri. Journal of Magnetism and Magnetic Materials 284 (2004) 416-422 